Journal homepage: http://www.interscience.org.uk

DOI: $10.18535 /$ ijahm/v7i4.03

Impact factor: 4.415

\title{
Yoga And Diabetes Mellitus: Recommendations And Benefits- Systematic Review
}

\author{
${ }^{1}$ Dr. Yadav Sunil Kumar , , Dr. Jain Nishi \\ ${ }^{1}$ Assistant Professor, Dept. of Sharira Rachana, NIA, Jaipur. \\ ${ }^{2} \mathrm{Ph} . \mathrm{D}$ Scholar, Dept. of Sharira Rachana, NIA, Jaipur.
}

\begin{abstract}
Background Yoga is a psycho- somatic -spiritual regulation for attaining union and synchronization between our mind, body and soul and definitive union of our individual realization and universal realization. The present literature review was aimed to assess the effectiveness and physiological effects of practicing Yoga on type 2 Diabetes Mellitus. Surya namaskar, Padmasana, Pashimottanasana, Ardhmatsyendrasana, Pawanmuktasana, Bhujangasana, Vajrasana, Dhanurasana, Savasana, Halasana, Sarvangasana, Matsyasana, Shalabhasana, Padahastasana are recommended in DM.

Materials and Method Appropriate articles on physiological effects of yogic practices including Pranayama from journals, books and online publications were re-evaluated for further assessment to drawn fruitful conclusion.

Discussion Physiological effect of practices of Asana, Pranayama and meditation on patho- physiological causes of DM as insulin resistance due to obesity, improper secretion or absence of secretion of insulin hormone due to chronic or uncontrolled case of type $2 \mathrm{DM}$ and stress has been mentioned.

Conclusion The reviewed articles haven't report any adverse effects for Yoga practice. The uniqueness of Yoga to alleviate stress is effective and incomparable. It is highly effective in early onset of disease and supportive or accessory treatment in chronic or uncontrolled case of type 2 DM. It can be administered as alternative therapy to standard lifestyle interventions.
\end{abstract}

Keywords Asana, Pranayama, Type 2 Diabetes Mellitus, Yoga

\section{Background}

Yoga is a psycho- somatic -spiritual regulation for attaining union and synchronization between our mind, body and soul and definitive union of our individual realization and universal realization. ${ }^{[1]}$ Yoga forms an essential part of mind/body strategies to encourage excellent physical condition and well being, which take account of relaxation procedures, hypnosis, visualization, feedback, meditation, breathing exercises, cognitive behavioural therapy and spirituality. ${ }^{[2]}$ These all strategies are based on researches into the associations and connections between the nervous, immune and endocrine systems, all of which make up source of psycho-neuro-endocrino-immunology. ${ }^{[3]}$

The use of alternative adjuvant therapies be based on substantiation from clinical investigation and researches and currently there is inadequate conceptual, comprehensive, methodical and systemic review in the existing literature that concentrates on the effectiveness and significance of Yoga practice in Diabetes Mellitus management as type 2 diabetes is fast becoming one of the foremost disabling diseases globally. ${ }^{[4]}$ The present literature review was aimed to assess the effectiveness and physiological effects of practicing Yoga on type 2 Diabetes Mellitus.

\section{Materials and Method}

In order to provide a general overview and understanding, appropriate articles on physiological effects of yogic practices including Pranayama from journals, books and online publications were re-evaluated. The list of references for each of the relevant studies was searched. Full text of relevant articles was retrieved for further assessment to drawn fruitful conclusion. 
${ }^{1}$ Dr. Yadav Sunil Kumar , International Journal of Ayurvedic \& Herbal Medicine 7(4) July.-Aug.2017 (2651-2655)

\section{Various Asana recommended in DM}

Surya Namaskar ${ }^{[5]}$ : It energies neuroglandular and neuro muscular system of body and ensures balanced supply of oxygenated blood, thus strengthening entire psychosomatic system of human body.

Vajrasana $^{[6]}$ : It is conducive to stabilize body mind, improves digestion and circulation along with strengthening thigh muscles.

Pawanamuktasana $^{[7]}$ : It is effective in muscular ailments, removes indigestion, builds powerful abdomen.

Padmasana $^{[8]}$ : Induces mental calmness and tranquility. Helps to relieve constipation, improves digestive process and tones coccygeal and sacral nerves by supplying them with extra flow of blood. It helps to keep wind, bile and phlegm in proper proportion.

Paschimottanasana $^{[9]}$ : Ensures proper circulation of blood in whole body. Stimulating digestive organs, encouraging regular bowel movements and relieving constipation, regulating working of pancreas and massaging abdominal organs.

Halasana $^{[10]}$ : Related to endocrine glands mainly thyroid gland.

Sarvangasana $^{[1]}$ : Rejuvenates entire body, toned up endocrine gland, helpful in DM, most effective for stream lining both body and mind, for relieving minor ailments, tension and feelings of sluggishness.

Matsyasana $^{[12]}$ : Helpful in DM, menstrual flow becomes regular normal.

Bhujangasana $^{[13]}$ : Massages abdominal organs, influences kidney and adrenal glands, more effective for dyspepsia, tones ovaries and uterus. Help massage adrenal gland to keep in good working order as it help to control our response to stress and metabolism.

Shalabhasana ${ }^{[14]}$ : Good for blood circulation, bring large supply of blood to kidneys and other organs thus cleaning and regenerating them. Stimulates whole ANS particularly parasympathetic. Abdominal organs are well massaged.

Dhanurasana $^{[15]}$ : effects entire abdominal region, liver pancreas are made to work in sound manner. Blood is encouraged to flush through whole system and hence there is good venous drainage, act as cleansing process, stimulates peristalsis, helpful in DM. By massaging pancreas, it helps to balance and regulate secretion of glycogen and insulin.

Padahastasana $^{[16]}$ : in indigestion, removes excess fat from abdomen.

Ardhamatsyendrasana $^{[17]}$ : Stimulates gastric secretions, liver, pancreas and spleen disorders. It compresses alimentary canal and almost all viscera.

Savasana $^{[18]}$ : It is intended to rejuvenate body, mind, and spirit. It is for relaxation.

\section{Studies supporting role of Yoga on DM}

Rejuvenation/regeneration of cells of pancreas due to abdominal stretching during Yoga exercise, may increase utilization and metabolism of glucose in peripheral tissues, liver, and adipose tissues through enzymatic process. ${ }^{[19]}$ Regeneration of pancreatic beta cells could occur by Yoga exercises that promote blood circulation in the region of the pancreas. ${ }^{[20]}$

Fasting blood sugar (FBS), serum total cholesterol, low density lipoproteins (LDL), very low density lipoproteins (VLDL), the ratio of total cholesterol to HDLC, and total triglycerides were significantly lower, and HDLC significantly higher. ${ }^{[21]}$

In a study involving 20 patients with type 2 diabetes mellitus were subjected to 40 days Yoga routine by an expert Yoga teacher. The postures performed were: Surya namaskar (sun salutation), Trikonasana (triangle pose), Tadasana (mountain pose), Padmasana (lotus pose), Bhastrika Pranayama (breathing exercise), Pashimottanasana (posterior stretch), Ardhmatsyendrasana (half spinal twist), Pawanmuktasana (joint freeing series), Bhujangasana (cobra pose), Vajrasana (thunderbolt pose), Dhanurasana (bow pose), and 
Shavasana (corpse pose). At the end of 40 days of performing the Asanas, the study participants had a significant decrease in fasting glucose levels, waisthip ratio and beneficial changes in insulin levels. ${ }^{[22]}$

\section{Physiological effect}

The metabolic effect of the practices of Asana, Pranayama and meditation synergize with other physical effects and contribute to physical fitness and sense of well-being. When it practiced over a period of time, it considerably reduces the metabolic rate due to decreased sympathetic nervous system activity.

Yoga has developed as a holistic approach to combat work-related stress, anxiety and depression in this epoch of modernization and exacerbation. Stress activates the oxidation process at membrane lipid level, disrupting the membrane, and causing release of oxygen at tissue level to relieve hypoxia. This tissue hypoxia plays important role in pathogenesis of cardiovascular disease and diabetes. ${ }^{[23]}$ High level of stress leads to increased cortisol level, which causes mobilization of fatty acids from fat stores, leading to higher level of abdominal fat. ${ }^{[2]}$ In anxiety disorders, the increase in thalamic GABA levels observed after Yoga practice explains the improvement in anxiety disorder, depression and multiple sclerosis where lower GABA levels were found. ${ }^{[25]}$

Physical and mental stress causes rise in BP and increase capillary hydrostatic pressure, facilitating flow of plasma from vascular compartment to the interstitial compartment- thus rising blood viscosity in capillaries, which is cardiovascular risk. ${ }^{[26]}$ Pranayama alleviate stress and decrease cardiovascular risk in DM.

Yoga practices over prolonged period causes significant drop in levels of blood sugar level, glycated haemoglobin and a rise in haemoglobin ${ }^{[27]}$, improves posture, circulation, BMI and contributes to sense of well being.

\section{Discussion}

This review focussed the beneficial effect of Yoga on DM. Yoga as mind body therapeutic approach is gaining greater admiration and recognition in conventional medicine as a holistic practice aimed toward achieving health.

The Patho-physiological cause of DM in general is insulin resistance caused due to obesity and improper secretion or absence of secretion of insulin hormone due to chronic or uncontrolled case of type 2 DM. Specialized causes include stress and lack of sleep due to various lifestyle modifications.

Obesity is one of the causes of DM because accumulated peripheral adipose cell causes the insulin resistance and preferably central obesity is primary cause of DM. Accumulated adipocytes induce the insulin resistance among the cell. Asana which reduces the abdominal obesity can be adopted which increase the insulin acceptance among the cells and reduces the peripheral fat accumulation with increased utilization of glucose in muscles, liver and adipose tissues.

By imparting the massaging effect over the pancreas may help to secrete the hormone by initiating the Beta cells rejuvenation in pancreas in case of chronic or uncontrolled case of type $2 \mathrm{DM}$ where there is improper or absence of insulin secretions. Yoga Asana which initiates the secretion of insulin hormone can be adopted. Twisting movement of Yoga helps in squeezing insulin out of pancreas thus helping in treating DM.

Asana and Pranayama increases nerve conduction velocity, reverse decline in cognitive brain function, release stress and mental fatigue, strengthens limbic system. ${ }^{[28]}$ Hence Asanas which reduces stress also recommended in DM.

In summary, various Yoga positions or postures are especially useful to reduce the fats in various parts, improves blood circulation of internal organs and strengthening them, stimulates the endocrine glands. It shows marked improvement in following criteria:

Metabolic effect: decrease blood glucose, lipids, cholesterol level and nitrogen in urine, increase protein in blood.

Physiological: BP constant, increase vital capacity, decrease respiration and pulse rate, weight becomes appropriate, chest circumference increases, abdomen circumference decreases, maintain stress fright conditions by increasing Adrenal cortex functions. 
Psychological: mentally fit and stable, decrease mental fatigue and stress. Balance between Sympathetic \& Parasympathetic N.S. Alpha waves increases, reconditioning of neuromuscular, reticular and limbic system thereby health and immunity increases.

\section{Conclusion}

The reviewed articles haven't report any adverse effects for Yoga practice. Any form of exercise can reduce abdominal fat but the uniqueness of Yoga to alleviate stress is effective and incomparable. It is highly effective in early onset of disease and supportive or accessory treatment in chronic or uncontrolled case of type 2 Diabetes mellitus. A definite recommendation is needed to encourage patients to practice Yoga. It can be administered as alternative therapy to standard lifestyle interventions.

\section{References}

1. Madanmohan, Mahadevan SK, Balakrishnan S, Gopalakrishnan M, Prakash ES. Effect of 6 wks Yoga training on weight loss following step test, respiratory pressures, handgrip strength and handgrip endurance in young healthy subjects. Indian J Physiol Pharmacol. 2008;52:164-70.

2. Bijlani RL, Vempati RP, Yadav RK, Ray RB, Gupta V, Sharma R, et al. A brief but comprehensive lifestyle education program based on Yoga reduces risk factors for cardiovascular disease and diabetes mellitus. J Altern Complement Med. 2005;11:267-74.

3. Balaji PA, Varne SR, Sadatali S. Effects of Yoga pranayama practices on metabolic parameters and anthropometry in type 2 diabetes. International Multidisciplinary Research Journal. 2011;1:1-4.

4. Global report on Diabetes. World Health Organization. Geneva. 2016.

5. Swami Shivapremananda. Step by step Yoga for Stress Relief.2003.New Delhi: New Age Books. Pg 108.

6. Swami Akshaya Atmanand. Yoga and Yogasan.2001.New Delhi: Pratibha Pratishthan. Pg 134.

7. Paraddi Kusuma Mallapa, Ganesh Shankar. Ashtanga Yoga in relation to Holistic health. 2006. New Delhi: Satyam Publishing House. Pg 112.

8. Swami Akshaya Atmanand. Yoga and Yogasan.2001.New Delhi: Pratibha Pratishthan. Pg 137.

9. Swami Shivapremananda. Step by step Yoga for Stress Relief.2003.New Delhi: New Age Books. Pg 85.

10. Swami Akshaya Atmanand. Yoga and Yogasan.2001.New Delhi: Pratibha Pratishthan. Pg 137.

11. Swami Shivapremananda. Step by step Yoga for Stress Relief.2003.New Delhi: New Age Books. Pg 72.

12. Swami Shivapremananda. Step by step Yoga for Stress Relief.2003.New Delhi: New Age Books. Pg 78.

13. Swami Shivapremananda. Step by step Yoga for Stress Relief.2003.New Delhi: New Age Books. Pg 94.

14. Swami Shivapremananda. Step by step Yoga for Stress Relief.2003.New Delhi: New Age Books. Pg 98.

15. Swami Shivapremananda. Step by step Yoga for Stress Relief.2003.New Delhi: New Age Books. Pg 102.

16. Paraddi Kusuma Mallapa, Ganesh Shankar. Ashtanga Yoga in relation to Holistic health. 2006. New Delhi: Satyam Publishing House. Pg 120.

17. Swami Akshaya Atmanand. Yoga and Yogasan.2001.New Delhi: Pratibha Pratishthan. Pg 168.

18. J.L.Gupta "chaitanya". The Healing power of Yoga and Kundalini Tantra: Path to wellness and Enlightment. 2010. Delhi: Penman Publishers. Pg 129.

19. Dang KK, Sahay BK. Yoga and Meditation, Medicine update. In: Singh MM, editor. The Association of Physicians of India. Vol. 9. New Delhi: APICON, The Association of Physicians of India conference; 1999. pp.502-512. part 1, chapters 57 and 58.

Sahay BK, Murthy KJR. Long term follow up studies on effect of Yoga in diabetes. Diab Res Clin Pract. 1988;5(suppl.1):S655. 
${ }^{1}$ Dr. Yadav Sunil Kumar , International Journal of Ayurvedic \& Herbal Medicine 7(4) July.-Aug.2017 (2651-2655)

20. P.A.Balaji, Smitha R Varne, Syed Sadat Ali. Physiological Effects of Yogic Practices and Transcendental Meditation in Health and Disease. North American Journal of Medical Sciences. 2012 Oct; 4(10): 442-448.

21. Bijlani RL, Vempati RP, Yadav RK, Ray RB, Gupta V, Sharma R, et al. A brief but comprehensive lifestyle education program based on Yoga reduces risk factors for cardiovascular disease and diabetes mellitus. J Altern Complement Med. 2005;11:267-74.

Balaji PA, Varne SR, Sadatali S. Effects of Yoga pranayama practices on metabolic parameters and anthropometry in type 2 diabetes. International Multidisciplinary Research Journal. 2011;1:1-4.

22. Malhotra V, Singh S, Tandon OP, Sharma SB. The beneficial effect of Yoga in diabetes. Nepal Med Coll J. 2005;7:145-7.

23. Neena Sharma, et al. Yoga and glycemic profile in diabetics. International Journal of Medical Science and Public Health 2014; Vol 3 Issue 9: 1135-1140

24. Hegde SV, Adhikari P, Kotian S, Pinto VJ, D'Souza S, D'Souza V. Effect of 3-month Yoga on oxidative stress in type-2 diabetes with or without complications. Diabetes Care 2011;37:2208-10.

25. Streeter CC, Whitfield TH, Owen L, Rein T, Karri SK, Yakhkind A, et al. Effects of Yoga versus walking on mood, anxiety and brain GABA levels. A randomized controlled MRS Study. J Altern Complement Med 2010;16):1145-52.

26. Neena Sharma, et al. Yoga and glycemic profile in diabetics. International Journal of Medical Science and Public Health 2014; Vol 3 Issue 9: 1135-1140

27. Cerranque GA, Maldonado EF, Vera FM, Manzaneque JM, Blanca MJ, Soriano G, et al. Haematological and biochemical modulation in regular Yoga practitioners. Biomed Res 2012;23:176-82.

28. Adler R, Cohen N, Felton D. Psychoneuroimmunology: interactions between nervous system and immune system. Lancet 1995;345:99-103. 